\title{
Molecular Characterization of Metallothionein Genes in Plants
}

\author{
Li-Hua YU*,*, Jin-Yuan LIU**, Masaaki UMEDA*, Hirofumi UCHIMIYA* \\ *Institute of Molecular and Cellular Biosciences, University of Tokyo, \\ Yayoi 1-1-1, Bunkyo-ku, Tokyo 113-0032, Japan \\ **Department of Biological Sciences and Biotechnology, Tsinghua University, Beijing 100084, China
}

Received 3 September 1998; accepted 18 September 1998

\begin{abstract}
Metallothioneins (MTs) are a family of cysteine (Cys)-rich, low-molecular-weight proteins ubiquitously presented in animals, fungi, cyanobacteria and plants. There have been a number of reports concerning the molecular cloning and characterization of genes encoding metallothionein (MT) in plants. The precise function of plant MTs is not yet clear. Nevertheless, the evidence suggests that MTs may be related to metal detoxification and other environmental stresses. Recent developments in studies on plant MTs will be discussed.
\end{abstract}

\section{Introduction}

Metallothioneins (MTs) are a family of cysteine (Cys)-rich, low-molecular-weight proteins which are found ubiquitously in animals, fungi, cyanobacteria and plants. In mammals, one MT can chelate seven bivalent metal ions by 20 Cys residues to form a structure consisting of two clusters, i.e. $\alpha$ and $\beta$ domains (Fig. 1-A) [1,2]. MTs are commonly believed to be involved in metal homeostasis and the detoxification of heavy metals. Under normal conditions, MTs function in the storage and mobilization of essential metals such as zinc and copper. However, when the organism faces a toxic metal such as cadmium, MTs act as scavengers to protect cells against metal toxicity $[1,3]$.

Over the past decade, many MT-like protein genes have been found in plants. There has been considerable interest in their structure and expression, with the aim of better understanding their role in plant metabolism. Although the exact function of plant MTs remains unclear, it seems that plant MTs are not solely associated with metal ions, but may also be related to other factors such as senescence and nonmetal stresses [4-10].

\section{Classification of plant MTs}

The deduced MT proteins can be classified into three classes based on the arrangement of Cys residues. Class I MTs are translational monomers with two Cys-rich clusters separated by a spacing region. Several class I MT genes have recently been identified in both monocots $[6,11,12]$ and dicots $\left[13^{-}\right.$
15]. Based on the arrangement of Cys residues in their amino- and carboxy-terminals, they can be divided into several types (Table 1). Class II MTs are translational monomers in which Cys residues are scattered throughout the entire sequence, e.g. Ec (early Cys-labeled) protein from wheat [16]. Class III MTs, i.e. phytochelatins, are synthesized from glutathione and/or $\gamma$-glutamylcysteine precursors by

(A)

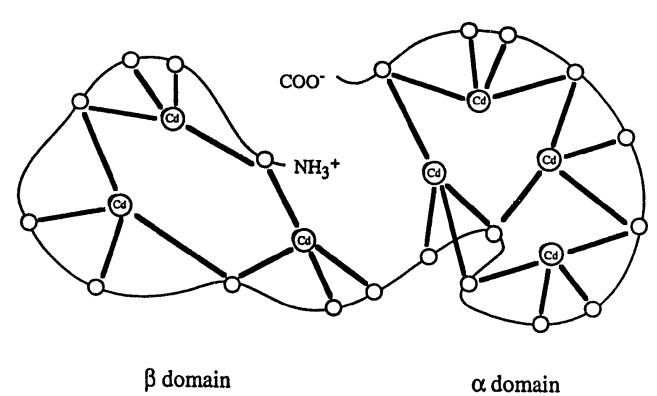

(B)



Fig. 1 Schematic representation of a metal-MT complex. (A) The $\mathrm{Cd}_{7}-\mathrm{MT}$ structure in mammals, which contains $4 \mathrm{Cd}^{2+}$ in the $\alpha$ domain and 3 $\mathrm{Cd}^{2+}$ in the $\beta$ domain $[1,2]$. (B) The putative structure for PsMT $_{\mathrm{A}}$ associated with metal ions [14]. The open circles in both (A) and (B) represent the location of Cys in the MT peptide chains. 
Table 1. Classification of class I MTs in plants.

\begin{tabular}{cll}
\hline Type & Featuer of Cys-rich domains at amino- and carboxy- terminal regions ${ }^{\mathrm{a}}$ & Reference \\
\hline 1 & CXCXXXCXCXXXCXC......CXCXXXCXCXXCXC & {$[6,11,14]$} \\
2 & CCXXXCXCXXXCXCXXXXXC.....CXCXXXCXCXXCXC & {$[15,29]$} \\
3 & CXCXXXCXCXXXCXC......XXCXCXXXCXCXXXCXC & {$[5,15]$} \\
4 & CCXXXCXCXXXCXCXXXXXC......CXCXXCXCXXXC(X) XCXCCXC & {$[12 ;$ EMBL/GenBank } \\
& & accession number U77294 $]$ \\
5 & CXXCXCXXXXXC......CXCXXXCXCXXCXC(C) & {$[13,29]$} \\
\hline
\end{tabular}

a " $C$ " and " $\mathrm{X}$ " represent a Cys residue and an amino acid residue other than Cys, respectively, and "......" represents the intermediate region between the two Cys-rich domains. (X) indicates that RicMT lacks a serine residue which is present in KCDL1016 (EMBL/Gen Bank accession number u77294). (C) indicates that pKIWI503 [29] lacks a cysteine residue which present in MT3 [13].

phytochelatin synthase [17]. They are composed of peptide chains of variable length [2].

\section{Molecular characteristics of MTs}

In plants, early analogues of MTs are phytochelatins, small metal-binding peptides composed of poly $(\gamma$-glutamylcysteinyl $)$ glycine, or $(\gamma \mathrm{EC}) \mathrm{nG}$, where $\mathrm{n}$ varies from two to 11 in different species [ $[18$, 19]. In Cd-tolerant cells of Datura innoxia, over $80 \%$ of the cellular $\mathrm{Cd}$ is bound to phytochelatins [20]. As mentioned above, phytochelatins are synthesized by phytochelatin synthase. This synthase is tetrameric and constitutively present in cells. However, enzyme activation requires heavy metal ions. In Silene cucubalus, cadmium is the strongest activator, and the activated enzyme catalyzes the transfer of the $\gamma$-EC moiety of glutathione to an acceptor glutathione or a growing chain of $(\gamma \mathrm{EC}) \mathrm{nG}$ oligomers to form phytochelatins [21]. Phytochelatins in plants were once regarded as counterparts of MTs in animals because they are found extensively in plants and detoxify excess metal ions. However, the discovery of translational MTs (Class I and Class II) in plants weakened this hypothesis. Phytochelatins may best be considered an undifferential response of all plant cells to non-essential metal ions [22].

Ec protein from wheat is a model class II MT in plants. Kawashima et al. [16] analyzed the structure of the Ec gene and found that they are single-copy and intronless, and are located in the long arms of chromosomes $1 \mathrm{~A}, 1 \mathrm{~B}$ and $1 \mathrm{D}$ in hexaploid wheat. A homolog of abscisic acid-responsive element was found in the 5 -flanking sequence, along with a putative TATA box, two inverted-repeat sequences and one directrepeat sequence. However, no sequences were similar to the MRE (metal-responsive element). Northern blot analysis revealed that the Ec gene is expressed abundantly in immature embryos, but declines rapidly upon germination. Corresponding to its genomic structure, the Ec gene was inducible by the addition of abscisic acid (ABA), but not $\mathrm{Zn}^{2+}$ to the medium for germinated wheat embryos. The open reading frame encodes 81 amino acids with 17 Cys residues, 14 of which form CXC motifs. Lane et al. [23] purified the Ec protein and found that it combined with $\mathrm{Zn}^{2+}$ at a ratio of 1: 5 . It has been suggested that Ec protein may be involved in zinc homeostasis during early embryogenesis in wheat, similar to the mammalian $\mathrm{Zn}^{2+}$ metallothionein [24].

Class I metallothioneins are the most puzzling and attractive group. Since the first full-length class I MT gene was reported in the flowering plant Mimulus guttatus [25], many more have been identified in a variety of plant species including pea [26], maize [11], soybean [27], Arabidopsis [13, 15,28], Vicia faba [8], rape [5], kiwifruit [29], Sambucus nigra L. [4], wheat $[10]$, rice $[6,9,12,30]$, tobacco [7], cotton [31] and tomato [32]. More information on these class I MT genes is shown in Table 2.

\section{1 Genomic organization of class I MT genes}

The genomic localization of the MT gene has been reported only in Arabidopsis. Zhou and Goldsbrough [15] mapped MT1a and MTIc (both type 3) to chromosome I, MT1b (type 3) and MT2b (type 2) to chromosome V, and MT2a (type 2) to chromosome III.

Southern blot analysis showed that several MT genes exist as small gene families such as the type 1 $M T s$ in pea [26], maize [11] and cotton [31], and the type $2 M T s$ of Arabidopsis [28] and Sambucus nigra L. [4]. More than one MT gene of the same type has been isolated from one plant species in Arabidopsis [15], cotton [31], Vicia faba [33] and tomato [32]. In the open reading frame, the type $1 M T$ s have one intron in pea $\left(P S M T_{\mathrm{A}}\right)$ [26], rice $(r g M T)$ [6] and maize $(M T-L)[11]$, and two introns in cotton $(M T 1$ $-A$ ) [31]; while the type 2 MTs have one intron in tomato $\left(L e M T_{\mathrm{B}}\right)$ [32].

In the $5^{\prime}$-noncoding sequence of MT genes, a putative MRE (metal-responsive element) moiety was 
Table 2. Summary of class I MTs in plants.

\begin{tabular}{|c|c|c|c|c|c|c|}
\hline Source & Gene & Type & Length/aa & Intron* & $\begin{array}{c}\text { Accession No.in } \\
\text { DDBJ/EMBL/GenBank* }\end{array}$ & Reference \\
\hline \multirow{2}{*}{$\begin{array}{l}\text { Actinidia deliciosa } \\
\text { (kiwifruit) }\end{array}$} & pKIWI503 & 5 & 63 & $?$ & L27811 & [29] \\
\hline & pKIWI504 & 2 & 78 & $?$ & L27813 & [29] \\
\hline \multirow[t]{4}{*}{ Arabidopsis thaliana } & $M T 1 a$ & 3 & 45 & $?$ & U11253 & [15] \\
\hline & $M T 1 b$ & 3 & 45 & $?$ & U11255 & [15] \\
\hline & $M T 2 b$ & 2 & 77 & $?$ & U11256 & [15] \\
\hline & $M T 3$ & 5 & 69 & ? & $?$ & {$[13]$} \\
\hline $\begin{array}{l}\text { Brassica campestris } \\
\text { (rape) }\end{array}$ & LSC54 & 3 & 45 & ? & L31940 & {$[5]$} \\
\hline $\begin{array}{r}\text { Glycine max } \\
\text { (soybean) }\end{array}$ & soybean $M T$ & 2 & 79 & $?$ & $?$ & {$[27]$} \\
\hline $\begin{array}{l}\text { Gossypium hirsutum } \\
\text { (cotton) }\end{array}$ & $M T 1-A$ & 1 & 75 & 2 & $Z 54188$ & {$[31]$} \\
\hline Lycopersicon & $L e M T_{\mathrm{A}}$ & 2 & 72 & $?$ & Z68309 & [32] \\
\hline $\begin{array}{l}\text { esculentum } \\
\text { (tomato) }\end{array}$ & $L e M T_{\mathrm{B}}$ & 2 & 82 & 1 & L77966 & [32] \\
\hline Mimulus guttatus & Mimulus $M T$ & 1 & 72 & $?$ & X51933 & {$[25]$} \\
\hline $\begin{array}{l}\text { Nicotiana glutinosa } \\
\text { (tobacco) }\end{array}$ & $M T$ & 2 & 81 & $?$ & U46543 & {$[7]$} \\
\hline \multirow{3}{*}{$\begin{array}{l}\text { Oryza sativa } \\
\text { (rice) }\end{array}$} & $r g M T$ & 1 & 74 & 1 & U18404 & {$[6]$} \\
\hline & $O s M T-2$ & 2 & 82 & $?$ & U43530 & {$[9]$} \\
\hline & ricMT & 4 & 80 & $?$ & AB002820 & [12] \\
\hline $\begin{array}{l}\text { Pisum sativum } \\
\quad \text { (pea) }\end{array}$ & $P S M T_{\mathrm{A}}$ & 1 & 75 & 1 & Z23097 & {$[26]$} \\
\hline Sambucus nigra & JET12 & 2 & 76 & ? & X83439 & {$[4]$} \\
\hline $\begin{array}{l}\text { Triticum aestivum } \\
\text { (wheat) }\end{array}$ & wali1 & 2 & 75 & $?$ & L11879 & {$[10]$} \\
\hline \multirow{2}{*}{$\begin{array}{l}\text { Vicia faba } \\
\quad \text { (fava bean) }\end{array}$} & $M T 1 a$ & 1 & 77 & $?$ & X91077 & [33] \\
\hline & $M T 1 b$ & 1 & 75 & $?$ & X91078 & {$[33]$} \\
\hline $\begin{array}{l}\text { Zea mays } \\
\quad(\text { maize })\end{array}$ & $M T-L$ & 1 & 76 & 1 & S57628 & [11] \\
\hline
\end{tabular}

*“?" means unkown.

identified in pea [26] and tomato [32], but not in cotton [31]. MREs exist in the promoter region of animal MTs and function as metal ion-dependent enhancers of the induction of MT transcription [34]. An increase in the number of MREs in the promoter increased the transcription level of the rat $M T-1$ gene in vivo [35]. Deletion mutation analyses revealed the core MRE to be $5^{\prime}$ TGCRCBCG 3 ', where R represents a purine and B can be any base but A $[36,37]$. In pea (Pisum sativum L.), Evans et al. [26] detected the sequence $5^{\prime}$ TGCACACC $3^{\prime}$ between -241 and -248 bases upstream of the $P_{S} M T_{\mathrm{A}}$ open reading frame. This sequence may have lost its metal-responsive function because the sixth position is A instead of G, $\mathrm{C}$ or $\mathrm{T}$, but no data are available to support this suggestion. Another MRE-like sequence was found in tomato $L e M T_{\mathrm{B}}$, i.e. the $5^{\prime}$ TACGCGCG $3^{\prime}$ sequence between -488 and -495 bases upstream from the start codon of the gene [32].

In addition to the MRE, a G-box-like motif (CAC-
GTG) was found between -145 and -150 bases of $L e M T_{\mathrm{B}}$, which may be stress-responsive [32]. Ethylene-responsive elements have also been identified in the promoter regions of $L e M T_{\mathrm{B}}$ [32] and $P S M T_{\mathrm{A}}$ [26]. On the other hand, a putative TATA box was found in the $5^{\prime}$ upstream region of $M T 1-A$ in cotton [31] and $M T-L$ in maize [11], as well as $P S M T_{\mathrm{A}}$ in pea [26] and $L e M T_{\mathrm{B}}$ in tomato [32].

Hudspeth et al. [31] tried to characterize the promoter of MT gene in cotton by transgenic method. The $640 \mathrm{bp}$ of the $5^{\prime}$-flanking region of $M T 1-A$ was ligated to the uidA gene and introduced into cotyledon explants of cotton. The strongest signal for GUS expression was found near the root tip, which was regarded to be the most sensitive to heavy metals. Thus, they suggested that $M T 1-A$ has a protective function despite the absence of the MRE consensus.

\section{1. 1 Differential expression of class I MTs}

The class I MTs reported so far can be divided into 
five types (Table 1). Many pieces of evidence support the idea that type 1 MTs are the most abundant in roots. Evans et al. [26] characterized the type 1 $P S M T_{\mathrm{A}}$ in pea, which was highly expressed in roots, weakly expressed in green and etiolated leaves, and most weakly expressed in developing cotyledons. The mRNA of the maize $M T-L$ (type 1) gene was the most abundant in roots, less abundant in green leaves and pith, and much less abundant in kernels [11]. Similarly, the type 1 MT from Mimulus guttatus showed a lower transcript level in leaf tissue than in roots [25]; Hsieh et al. [6] reported that the constitutive expression of $\mathrm{rgMT}$ (type 1) was as much as 8 -fold and 1. 5-fold higher in roots than in sheaths and leaves, respectively.

In addition, type 2 MT transcripts preferentially accumulate in aerial tissues, especially leaves, as in soybean $M T$ [27], rice $O s M T-2$ [9] and $L e M T_{\mathrm{A}}$, $L e M T_{\mathrm{B}}$ from tomato [32]. In Vicia faba, Foley and Singh [8] demonstrated through Northern blot analysis that type 2 MT was expressed abundantly in leaves, stems and flowers, and at a low level in roots, but was absent in mesophyll protoplasts. Moreover, using ${ }^{32} \mathrm{P}$-labeled MT transcripts as probes, they performed in situ hybridization on leaf sections and observed predominant signals at the site of trichome. In kiwifruit, the type 2 MT $p K I W I 204$ was expressed most abundantly in young fruit (6 days after anthesis) [29].

Type 3 MTs have been reported only in Arabidopsis $[15,28]$ and rape [5]. The differential expression of the MT1 (type 3) gene was investigated in Arabidopsis. A higher level of transcripts was observed in roots than in leaves in both young and mature plants. On the other hand, the LSC54 in Brassica napus showed pronounced expression in senescing leaves and nearly no expression in roots, even though it is a type 3 MT with the same Cys arrangement in the two Cys-rich domains as Arabidopsis MT1 (Table 1).

The ricMT in rice is the only type $4 \mathrm{MT}$ gene for which the expression pattern has been investigated [12]. This gene seems to be expressed constitutively, and the strongest transcription signal for ricMT was detected in stems, at a level dozens of times higher than that in green leaves. A low level of ricMT transcript was observed in roots and endosperms.

A type 5 MT gene has been reported in kiwifruit, and the mRNA level was high in the late stage of fruit development [29]. Another type 5 MT was extracted from Arabidopsis as MT3, but little is known about its expression pattern [13].

Generally, class I MT genes are expressed constitutively in plants, with tissue-specific patterns. This differential expression depends on the features of the Cys-rich domain in type 1 and type 2, but varies in type 3. An analysis of the genomic structure of MTs and of the mechanism of genetic regulation may help to explain the relationship between the structure and the expression pattern of MTs.

\section{2 Expression pattern under the influence of vari- ous factors}

\section{2.1 metal ions}

As homologs of animal MTs, it would be reasonable to assume that the MTs in plants are related to metal metabolism and the detoxification of excess metal ions. Indeed, the expression of both Ec proteins and several class I MT genes varies under metal treatment. The wali1 (type 2) in wheat was originally isolated as an aluminum-induced gene. Its expression is also increased by treatment with other toxic metal ions such as $\mathrm{Cd}, \mathrm{Fe}, \mathrm{Zn}, \mathrm{Cu}, \mathrm{Ga}, \mathrm{In}$ and $\mathrm{La}$ [10].

In rice, the transcript level of $\operatorname{Rg} M T$ (type 1) was elevated by $250 \mu \mathrm{M} \mathrm{CuCl}_{2}$ in suspension-cultured cells [6], while $100 \mu \mathrm{M} \mathrm{CuSO}_{4}$ increased ricMT (type 4) transcripts in both shoots and roots of seedlings [12]. This expression-enhancing effect of $\mathrm{Cu}^{2+}$ has also been reported in type 2 MT genes from Arabidopsis [28] and tobacco [7], and in type 3 MT from Arabidopsis [28]. In contrast, copper ion has been shown to have a suppressive effect on type $2 \mathrm{MT}$ in soybean [27] and Vicia faba [8]; in the copper-tolerant plant Mimulus guttatus, transcription of the type 1 MT was inhibited by $5 \mu \mathrm{M} \mathrm{CuSO}_{4}$, as well as by $5 \mu \mathrm{M}$ $\mathrm{CdSO}_{4}$ and $15 \mu \mathrm{M} \mathrm{ZnSO}{ }_{4}$ [25]. In addition, the mRNA level of ricMT in the root of rice seedlings was reduced by $100 \mu \mathrm{M}$ aqueous solutions of $\mathrm{ZnSO}_{4}$, $\mathrm{CdCl}_{2}, \mathrm{FeCl}_{3}, \mathrm{~Pb}(\mathrm{Ac})_{2}$ and $\mathrm{AlCl}_{3}$, respectively [12].

In some cases, the effects of metal ions on MT expression seem to be tissue-specific and to depend on the type of metal ion. For example, under treatment with various metal ions including $\mathrm{Cu}, \mathrm{Zn}, \mathrm{Cd}, \mathrm{Fe}, \mathrm{Pb}$ and $\mathrm{Al}$, ricMT mRNA was slightly increased in shoots, but was decreased in roots except with copper [12]. On the other hand, the expression of type 1 MTs in Vicia faba was not significantly affected by treatment with $\mathrm{Cd}, \mathrm{Cu}, \mathrm{Fe}$ or $\mathrm{Zn}$ [33]. A small effect of metal ions has also reported in rice, where the OsMT-2 (type 2) transcript was slightly reduced by $\mathrm{Cu}$ or $\mathrm{Cd}$, and was barely affected in the presence of $\mathrm{Al}, \mathrm{Fe}, \mathrm{Pb}$ or $\mathrm{Zn}[9]$.

\section{2.2 Senescence}

Coupe et al. [4] isolated the type 2 MT gene JET12 from the abscission zones of ethylene-treated Sambucus nigra L. leaves. Northern analysis revealed that the JET12 gene was expressed only in senescent leaves, and in the ethylene-treated abscission zone. Similarly, the type 3 MT LSC54 in rape (Brassica napus) was expressed during leaf senescence, and as 
senescence progressed, the mRNA level of LSC54 increased [5]. Hsieh et al. [6] showed that the expression of $\operatorname{rg} M T$ (type 1) increased as young leaves progressed to senescence. These results suggest that these MT genes may play a role in the senescence-associated metabolism of plants.

\section{2.3 Other stresses}

Considerable effort has been made to clarify the relationships between plant MTs and environmental factors other than metal ions. The expression of type 2 MT seems to be easily affected by stresses. For example, the MT in tobacco was strongly induced by tobacco mosaic virus and wounding [7]; and the expression of MT in Vicia faba was reduced when plants were treated with salt, cold, salicylic acid or UV-light [8]. Furthermore, transcripts of OsMT-2 in rice could be induced by sucrose starvation, heat shock and abscisic acid [9]; and the expression of wali1 in wheat was increased by low-nutrient conditions and wounding [10].

Regarding type $1 \mathrm{MT}$, the mRNA level of $\operatorname{rg} M T$ in rice increased under treatment with heat shock, a toxicant (DMSO) and starvation, and decreased in the presence of abscisic acid [6].

\section{3 Discussion}

The function of a gene is generally dependent upon the structure of the protein it encodes. Therefore, the function can not be determined directly unless the protein is available. Unfortunately, the putative proteins of most of the class I MT genes isolated so far are unknown, probably due to their sensitivity to proteolysis [14]. Thus, it is difficult to clarify the roles of MTs in plants, since most of the available data are transcriptional and indirect, even though the mRNA levels of MTs have been shown to be tissuespecific and to be sensitive to a variety of factors such as hormones, heat shock, cold, salinity, UV-light, viruses, wounding, toxicants and starvation, as well as metal ions and senescence. It is fairly clear that MTs are stress-related and may be involved in metal metabolism and the detoxification of excess metals during plant development. However, much more work is necessary to understand MT-metal interaction and the mechanism of MT expression.

The greatest advances have been reported in Arabidopsis. By chromatography based on size, SH content and copper-affinity, Murphy et al. [13] identified MT1 (type 3) and MT2 (type 2) proteins from Arabidopsis, and the copper-binding capacity in vitro was in a copper: protein molar ratio of 7.3 for MT2 and 8.4 for MT1. Moreover, they confirmed by immunohybridization that MT1 was expressed substantially in roots while MT2 was expressed mainly in leaves, and the expressions of both MT1 and MT2 were enhanced by copper. These characteristics agree with previous mRNA-level analyses [15, 28].

The MTs of Arabidopsis have also been transformed into yeast and prokaryotes to investigate their relationship with metal ions. Zhou and Goldsbrough [28] found that both MT1 and MT2 expressed in an MT-deficient $\left(\mathrm{CUP}^{\triangle}{ }^{\triangleright}\right)$ mutant of yeast remedied heavy metal sensitivity and provided high resistance to copper. Robinson et al. [38] transferred MT2 into an endogenous $\mathrm{Zn}^{2+}$-MT gene-deficient cyanobacterium (Synechococcus PCC 7942) and found that MT2 partly complemented $\mathrm{Zn}^{2+}$ hypersensitivity. Moreover, the MT2 expressed in the transformed $E$. coli was shown to bind to $\mathrm{Zn}^{2+}$ in vitro. These results suggest that both MT1 and MT2 may be copper-inducible and MT2 may be zinc-resistant in Arabidopsis. Progress has been made in transgenic research on plant species other than Arabidopsis. Kille et al. [14] expressed the pea $P s M T_{\mathrm{A}}$ in $E$. coli and estimated $\sim 6$ g. atoms of cadium per mole of protein, and the none -Cys spacer region was found to be proteolysed, which implied that one integrated $\mathrm{PsMT}_{\mathrm{A}}$ may bind 12 bivalent metal ions. The putative model for the metal-binding PSMT $_{\mathrm{A}}$ protein is shown in Fig. 1-B. Evans et al. [39] also transferred $P S M T_{\mathrm{A}}$ into E. coli, as well as into Arabidopsis, and more copper had accumulated in both the transformed bacteria and plants than in the control group. On the other hand, MT1a and MT1b (both type 1) and MT2 (type 2) in Vicia faba were expressed in E. coli, and were able to bind $\mathrm{Cd}, \mathrm{Cu}, \mathrm{Zn}$, but not $\mathrm{Fe}$ [33]. In comparison, an MT gene from mouse was introduced into tobacco, and this increased the resistance of the plants to cadmium [40].

These data may suggest that MTs are stressrelated and may be involved in metal metabolism and the detoxification of excess metals during plant development. More work is necessary to better understand MT-metal interaction and the mechanism of MT expression.

\section{Acknowledgements}

This study was supported by a Grand-in-Aid for Scientific Research from the Ministry of Education, Science and Culture of Japan, and by a grant from the Rockefeller Foundation.

\section{References}

[1] Winge, D. R., Miklossy, K. A., 1982. J. Biol. Chem., 257: 3471-3476.

[2] Kägi, J. H. R., Schäffer, A., 1988. Biochemistry, 27: 8509-8515.

[ 3 ] Chernaik, M. L., Huang, P. C., 1991. Proc. Natl. Acad. Sci. USA, 88: 3024-3028. 
[4] Coupe, S. A., Taylor, J.E., Roberts, J. A., 1995. Planta, 197: 442-447.

[5] Buchanan-Wollaston, V., 1994. Plant Physiol., 105: 839-846.

[6] Hsieh, H. M., Liu, W.K., Huang, P.C., 1995. Plant Mol. Biol., 28: 381-389.

[ 7 ] Choi, D., Kim, H. M., Yun, H. K., Park, J. A., Kim, W. T., Bok, S. H., 1996. Plant Physiol., 112 : 353-359.

[ 8 ] Foley, R. C., Singh, K. B., 1994. Plant Mol. Biol., 26: $435-444$.

[9] Hsieh, H. M., Liu, W. K., Chang, A., Huang, P. C., 1996. Plant Mol. Biol., 32: 525-529.

[10] Snowden, K. C., Richards, K. D., Gardner, R. C., 1995. Plant Physiol., 107: 341-348.

[11] de Framond, A. J., 1991. FEBS Lett., 290: 103106.

[12] Yu, L.H., Umeda, M., Liu, J. Y., Zhao, N. M., Uchimiya, H., 1998. Gene, 206: 29-35.

[13] Murphy, A., Zhou, J., Goldsbrough, P. B., Taiz, L., 1997. Plant Physiol., 113: 1293-1301.

[14] Kille, P., Winge, D. R., Harwood, J. L., Kay, J., 1991. FEBS, 295: 171-175.

[15] Zhou, J., Goldsbrough, P. B., 1995. Mol. Gen. Genet., 248: 318-328.

[16] Kawashima, I., Kennedy, T. D., Chino, M., Lane, B. G., 1992. Eur. J. Biochem., 209: 971-976.

[17] Dhariwal, H. S., Kawai, M., Uchimiya, H., 1998. Plant Biotech., 15: 1-10.

[18] Grill, E., Winnacker, E. L., Zenk, M.H., 1986. FEBS Lett., 197: 115-120.

[19] Grill, E., Winnacker, E. L., Zenk, M. H., 1987. Proc. Natl. Acad. Sci. USA, 84: 439-443.

[20] Jackson, P. J., Unkefer, C. J., Doolen, J. A., Watt, K., Robinson, N. J., 1987. Proc. Natl. Acad. Sci. USA, 84: 6619-6623.

[21] Grill, E., Löffler, S., Winnacker, E. L., Zenk, M. H., 1989. Proc. Natl. Acad. Sci. USA, 86: 68386842.

[22] Macnair, M. R., 1993. New Phytol., 124: 541-559.

[23] Lane, B., Kajioka, R., Kennedy, T., 1987. Cell. Biol., 65: 1001-1005.

[24] Wong, K. L., Klaasen, C. D., 1979. J. Biol. Chem.,
254: 12399-12403.

[25] de Miranda, J. R., Thomas, M. A., Thurman, D. A., Tomset, A. B., 1990. FEBS Lett., 260: 277280.

[26] Evans, I. M., Gatehouse, L. N., Gatehouse, J. A., Robinson, N. J., Croy, R. R. D., 1990. FEBS Lett., 262: 29-32.

[27] Kawashima, I., Inokuchi, Y., Chino, M., Kimura, M., Shimizu, N., 1991. Plant Cell Physiol., 32: 913 $-916$.

[28] Zhou, J., Goldsbrough, P. B., 1994. Plant Cell, 6: 875-884.

[29] Ledger, S. E., Gardner, R.C., 1994. Plant Mol. Biol., 25: 877-886.

[30] Liu, J., Hara, C., Umeda, M., Zhao, Y., Okita, T. W., Uchimiya, H., 1995. Plant Mol. Biol., 29: 685 -689 .

[31] Hudspeth, R. L., Hobbs, S. L., Anderson, D. M., Rajasekaran, K., Grula, J. W., 1996. Plant Mol. Biol., 31: 701-705.

[32] Whitelaw, C. A., Huquet, J. A. L., Thurman, D. A., Tomsett, A. B., 1997. Plant Mol. Biol., 33: 503 $-511$.

[33] Foley, R.C., Liang, Z. M., Singh, K. B., 1997. Plant Mol. Biol., 33: 583-591.

[34] Culotta, V.C., Hamer, D. H., 1989. Mol. Cell. Biol., 9: 1376-1380.

[35] Anderson, R. D., Taplitz, S. J., Wong, S., Bristol, G., Larkin, B., Herschman, H. R., 1987. Mol. Cell. Biol., 7: 3574-3581.

[36] Karin, M., Haslinger, A., Holtgreve, H., Richards, R. I., Krauter, P., Westphal, H. M., Beato, M., 1984. Nature, 308: 513-519.

[37] Seguin, C., Hamer, D. H., 1987. Science, 235: 1383 $-1387$.

[38] Robinson, N. J., Wilson, J. R., Turner, J. S., 1996. Plant Mol. Biol., 30, 1169-1179.

[39] Evans, K. M., Gatehouse, J. A., Lindsay, W. P., Shi, J., Tommy, A. M., Robinson, N. J., 1992. Plant Mol Biol, 20: 1019-1028.

[40] Pan, A., Yang, M., Tie, F., Li, L., Chen, Z., Ru, B., 1994. Plant Mol. Biol., 24: 341-351. 